\title{
Thermo-Electrochemical Cells Based on Carbon Nanotube Electrodes by Electrophoretic Deposition
}

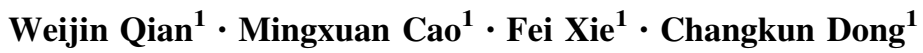

Received: 25 November 2015 / Accepted: 22 December 2015/Published online: 29 January 2016

(C) The Author(s) 2016. This article is published with open access at Springerlink.com

\begin{abstract}
Drawbacks of low efficiency and high cost of the electrode materials have restricted the wide applications of the thermo-electrochemical cells (TECs). Due to high specific areas and electrical conductivities, the low cost multi-walled carbon nanotubes (MWNTs) are promising alternative electrode materials. In this work, the MWNT films of up to $16 \mathrm{~cm}^{2}$ were synthesized on stainless steel substrates by the electrophoretic deposition (EPD) to make the thermo-electrochemical electrodes. MWNT electrodes based on TECs were characterized by cyclic voltammetry and the long-term stability tests with the potassium ferri/ferrocyanide electrolyte. The TECs reached the current density of $45.2 \mathrm{~A} \mathrm{~m}^{-2}$ and the maximum power density of $0.82 \mathrm{~W} \mathrm{~m}^{-2}$. The relative power conversion efficiency of the MWNT electrode is $50 \%$ higher than that for the Pt electrode. Meanwhile, the TECs was operated continuously for $300 \mathrm{~h}$ without performance degradation. With the priorities of low cost and simple fabrication, EPD-based MWNT TECs may become commercially viable.
\end{abstract}

Keywords Thermo-electrochemical cells · Carbon nanotubes · Electrophoretic deposition · Power conversion efficiency

\section{Introduction}

Harvesting of low grade heat $\left(<130{ }^{\circ} \mathrm{C}\right)$ is considered an effective sustainable energy source. Thermo-electrochemical cells (TECs) utilize the temperature-dependent electrochemical redox potentials to convert the thermal energy to electrical energy. Comparing with other thermal energy harvesting techniques, such as the thermoelectrics, thermocouples, and stirling engines [1-4], TECs have great potential for wide applications due to advantages of simple

The authors Weijin Qian and Mingxuan Cao contributed equally to this work.

Electronic supplementary material The online version of this article (doi:10.1007/s40820-016-0082-8) contains supplementary material, which is available to authorized users.

Changkun Dong

dck@wzu.edu.cn

1 Institute of Mirco-Nano Structure \& Optoelectronics, Wenzhou University, Wenzhou 325035, People's Republic of China design, maintenance-free, environment-friendly, and low cost.

As shown in Fig. 1a, the two half cells of the TECs are held at different temperatures, causing a difference in the redox potential of the mediator around the anode and cathode [5]. Electrons are generated at the anode due to the oxidation reaction of ferrocyanide. When traveling through the cathode, electrons would be consumed from the reduction reaction of ferricyanide. The ingredient of the electrolyte keeps almost unchanged owing to the balance of oxidized and reduced species in the solution [5]. As a result, the current and output power can be acquired continuously.

The electrode exchange current density is one of the most important factors in energy conversion for TECs. In practice, the current of TECs can be described from the relation: $I=V / R$, where $V$ represents the voltage between the two working electrodes, and the resistance $R$ consists of four parts, i.e., charge transfer, ohmic, solution diffusion, and thermal diffusion resistances [6,7]. To get high exchange current densities, the redox couples, such as the ferri/ferrocyanide electrolyte, are commonly selected in TECs $[8,9]$. In the selection of electrode materials, the 

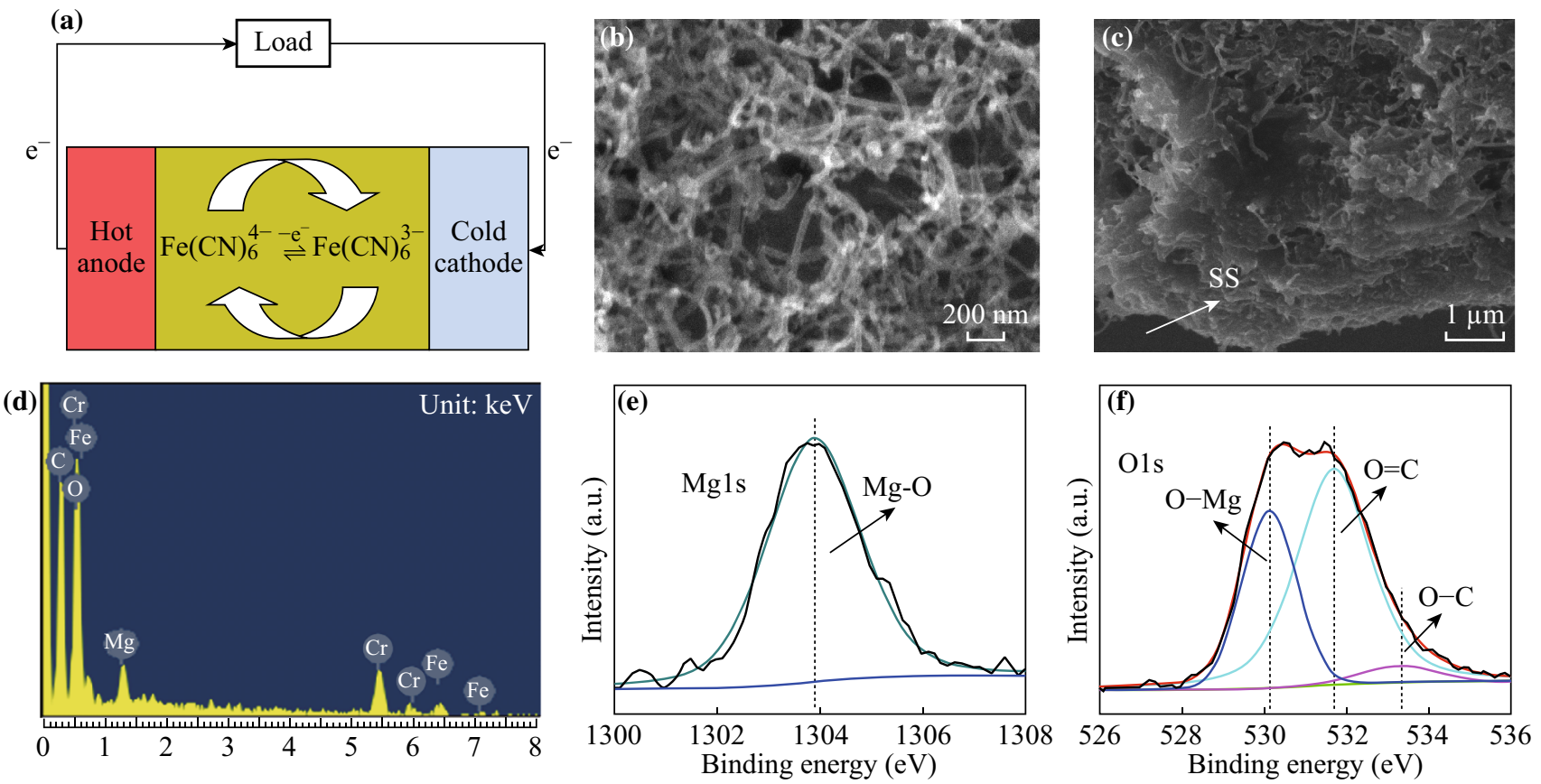

Fig. 1 a Schematic of a TEC with nanostructured electrodes showing concentration gradients of the ferri/ferrocyanide redox ions during power generation. b, c SEM images of MWNT film on stainless steel substrate. $\mathbf{d}$ EDS analysis of the MWNT electrode. e, $\mathbf{f}$ XPS spectra of Mg 1s and $\mathrm{O} 1 \mathrm{~s}$ for the MWNT sample

fast charge transfer property and low resistance at the electrode/electrolyte interface are important factors. Platinum is the conventional electrode material due to high surface catalytic activity for oxidation and reduction reactions. However, it is hard to promote Pt-based TECs in engineering fields due to high cost and low conversion efficiency [6, 8]. With the development of nanotechnology [10-13], carbon nanotubes (CNTs) have been employed in different electrochemical devices [14-18], such as lithium-ion batteries, supercapacitors, and fuel cells due to large specific surface area and high catalytic activity. Recently, applications of MWNTs in TECs are widely investigated [19-23]. In the preparation of the MWNT electrode, the chemical vapor deposition (CVD) growth is widely applied $[8,9,22]$. The MWNT TECs electrodes prepared by CVD show promising electrical contact and stability properties.

Electrophoretic deposition (EPD) is an effective technique to produce CNTs films with various advantages, including fewer requirements on the type \& shape of the substrate, large-scale production capability, and low cost [24]. In this work, we prepared the TECs electrodes by EPD of MWNTs on metal substrates. The TECs presented excellent long-term operation stability and substantial higher energy conversion efficiency than that for Pt-based TECs. This investigation suggests that EPD method may be applicable for MWNTs-based TECs.

\section{Experimental}

The MWNT material, with lengths from 10 to $30 \mu \mathrm{m}$, outer diameters of approximately $10 \mathrm{~nm}$, and purity of $>90 \%$, was purchased from XFNANO Materials. The MWNTs were first filtered and washed with acetone, then sonicated in concentrated nitric acid for $20 \mathrm{~h}$. After the processing, carboxylic and other oxygen-containing groups were decorated on MWNTs surfaces [24]. During EPD, the carboxylic MWNTs were first dispersed in ethanol $\left(0.1 \mathrm{~g} \mathrm{~L}^{-1}\right)$ and sonicated for about $1 \mathrm{~h}$. Then magnesium chloride powder material $\left(\mathrm{MgCl}_{2}\right.$, Aladdin) was added into the suspension. Subsequently, the stainless steel substrate (SS) and counter electrode were immersed into the suspension with distance of $1 \mathrm{~cm}$. Different substrates of surface areas from 0.5 to $16 \mathrm{~cm}^{2}$ were employed. After the deposition, the MWNT electrodes were annealed in vacuum at $750{ }^{\circ} \mathrm{C}$.

The morphologies of the MWNT film were observed by scanning electron microscopy (SEM; JEOL SM-6700F). The compositions of the as-prepared products were characterized by energy-dispersive X-ray analysis (EDS), and X-ray photoelectron spectroscopy (XPS; PHI 5000 VersaProbe). The tensile tests of the samples were carried out by Instron 3343 instrument to investigate the adhesion between MWNT films and the substrates with the uncertainty of about $15 \%$. During the test, the MWNT-SS 
sample was fixed by a clamp, and the MWNT film was wrapped by the adhesive tape. The tape grabbing the MWNT film was pulled away until the film peeled off from the substrate.

The cyclic voltammetry (CV) measurements were conducted using a Zahner IM6 electrochemical workstation. The 3 -electrode tests were conducted at room temperature with the $\mathrm{Ag} / \mathrm{AgCl}$ saturated in $\mathrm{KCl}$ solution as the reference electrode and a platinum foil as the counter electrode. CVs were tested using $0.1 \mathrm{M} \mathrm{K}_{4} \mathrm{Fe}(\mathrm{CN})_{6}$ aqueous solution with $0.5 \mathrm{M} \mathrm{NaCl}$ as the supporting electrolyte at the rate of $5 \mathrm{mV} \mathrm{S}^{-1}$.

The characteristic performances of the MWNT-based TECs, including the open-circuit potential $\left(V_{\mathrm{oc}}\right)$, the shortcircuit current $\left(I_{\mathrm{sc}}\right)$, and the output power, were investigated in I-shaped TECs and the stability was tested in the U-shaped TECs. The $0.4 \mathrm{M}$ potassium ferrocyanide $\left(\mathrm{K}_{4}\right.$ $\mathrm{Fe}(\mathrm{CN})_{6} \cdot 3 \mathrm{H}_{2} \mathrm{O}$, Aladdin) and ferricyanide $\left(\mathrm{K}_{3} \mathrm{Fe}(\mathrm{CN})_{6}\right.$, Aladdin) aqueous solution were employed as the electrolyte due to its high Seebeck coefficient [9]. For the I-shaped TECs, measurements were conducted in a glass tube with the internal diameter of $8 \mathrm{~cm}$ and the distance of two electrode of $5 \mathrm{~cm}$. The hot side temperature was controlled by the resistive heating and the cold side was immerged in an ice water with the temperature difference of $40{ }^{\circ} \mathrm{C}$. The electrode temperatures were measured by OMEGA thermocouple probes. The maximum power $\left(P_{\max }\right)$ generated by the MWNT electrodes could be attained when the external load resistance is equal to the internal resistance. For the U-shaped TECs, the distance between the two electrodes was $7 \mathrm{~cm}$ with the temperature difference of $15^{\circ} \mathrm{C}$. The hot side temperature $\left(40^{\circ} \mathrm{C}\right)$ was controlled by a resistive heater, and the cold side temperature $\left(25^{\circ} \mathrm{C}\right)$ was controlled by a recirculation water chiller. The potentials and currents generated from TECs were monitored using the KEITHLEY 2440 sourcemeter.

\section{Results and Discussions}

Typical morphologies and composition characterizations of the MWNT samples are shown in Fig. 1. The top and side SEM images of the MWNT films are presented in Fig. 1b, c. As shown in Fig. 1b, the MWNTs are randomly oriented on the SS substrate with diameters of $30-50 \mathrm{~nm}$. From the side SEM images (Fig. 1c), the MWNT film and $\mathrm{Mg}^{2+}$ form the pasting substance after the heat treatment. The EDS analysis result is shown in Fig. 1d. The signals of Fe and $\mathrm{Cr}$ are from the stainless steel substrate. The $\mathrm{O}$ signal mainly comes from the $\mathrm{MgO}$ due to the heat treatment of the products, while $\mathrm{MgO}$ could improve the adhesiveness between MWNTs and the substrate [25, 26], benefiting the efficiency and stability of TECs. XPS was applied to further investigate the composite of the film. As shown in
Fig. 1e, the Mg $1 \mathrm{~s}$ peak at $1303.9 \mathrm{eV}$ was detected, which was from the $\mathrm{Mg}-\mathrm{O}$ bond and higher than the peak of metallic $\mathrm{Mg}(\mathrm{Mg} 1 \mathrm{~s}$ at $\sim 1303 \mathrm{eV})$ [27]. For the $\mathrm{O} 1 \mathrm{~s}$ spectrum (Fig. 1f), three peaks at 530.1, 531.7, and $533.3 \mathrm{eV}$ could be assigned to the $\mathrm{O}-\mathrm{Mg}, \mathrm{O}-\mathrm{C}$, and $\mathrm{O}=\mathrm{C}$ bonds, respectively $[28,29]$. It is worth noting that the peak at $\sim 533.3 \mathrm{eV}$ should not be assigned to the peroxide magnesium species because the products were conducted through the annealing process at $750{ }^{\circ} \mathrm{C}$ [27]. The XPS analysis confirmed the existence of $\mathrm{MgO}$ species. The tensile test was conducted to investigate the function of $\mathrm{MgO}$ on the adhesion between the MWNT film and the substrate, as shown in Fig. 2. The maximum stresses of 12.38 and $6.95 \mathrm{~N}$ correspond to $\mathrm{Mg}^{2+}$ contents of 0.03 and $0.01 \mathrm{~g} \mathrm{~L}^{-1}$, respectively, showing clearly adhesion enhancement with the existence of $\mathrm{MgO}$. In addition, the lower concentration of $\mathrm{Mg}^{2+}\left(<0.03 \mathrm{~g} \mathrm{~L}^{-1}\right)$ would bring CNTs to form the inhomogeneous film on the SS substrate, and the excessive $\mathrm{Mg}^{2+}$ would decrease the conductivity of the CNTs electrode due to the formation of $\mathrm{MgO}$ after the annealing treatment.

Cyclic voltammetry (CV) tests were conducted to investigate the electroactive surface area (ESA) of the electrode materials, as shown in Fig. 3. ESA can be described as

$I_{P-f} \propto \sqrt{D v} C_{0} A$

[30-32], and the Faradaic peak current $I_{\mathrm{p}-\mathrm{f}}$ depends on the diffusion coefficient $(D)$, initial concentration $\left(C_{\mathrm{o}}\right)$, scan rate $(v)$, and electroactive surface area $(A)$. Generally, CV runs at low scan rates reflect the electrochemical equilibrium at electrode surfaces. The peak current of the MWNT electrode is larger than that of Pt with the same physical areas. Since both MWNT and the Pt show the reversible reactions, higher peak current for the MWNT electrode can be attributed to the increase of ESA. Under the scan rate of $5 \mathrm{mV} \mathrm{S}^{-1}$, the separations between the reduction and oxidation peaks for $\mathrm{Pt}$ and MWNT/SS electrodes are 65

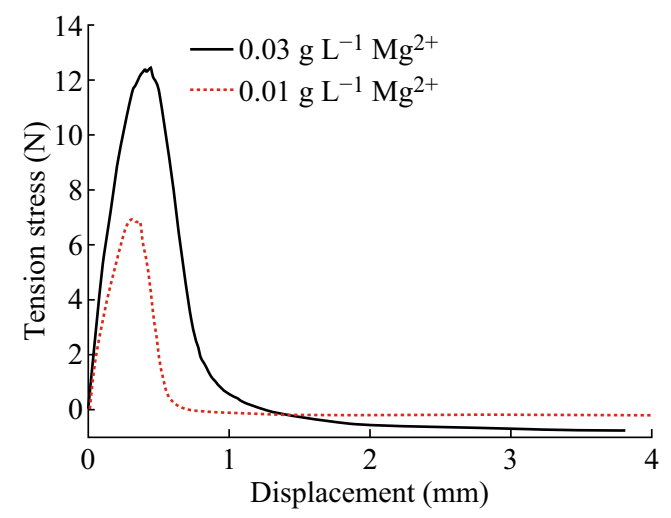

Fig. 2 Tensile test of the MWNT film adhesion with the existence of $\mathrm{MgO}$ 


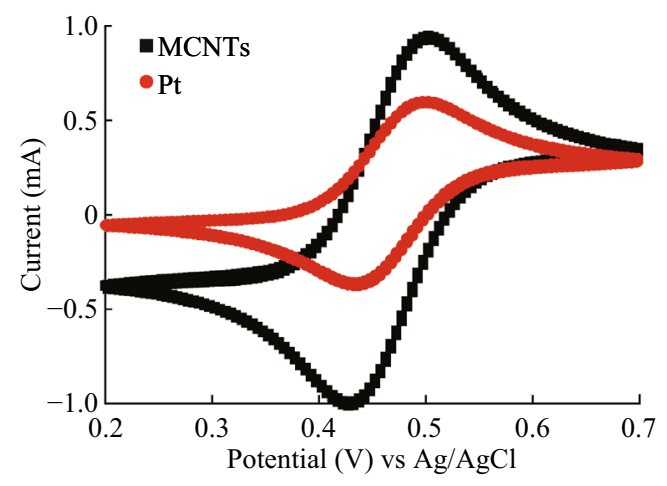

Fig. 3 Cyclic voltammograms for platinum foil and MWNT/SS electrodes in $100 \mathrm{mM} \mathrm{K}_{4} \mathrm{Fe}(\mathrm{CN})_{6}$ solution. Working electrode MWNT/SS plate or Pt foil of $1 \times 0.5 \mathrm{~cm}^{2}$, counter electrode $\mathrm{Pt}$ of $2.0 \times 2.0 \mathrm{~cm}^{2}$, reference electrode $\mathrm{Ag} / \mathrm{AgCl}$ in saturated $\mathrm{KCl}$ solution, scan rate $5 \mathrm{mV} \mathrm{S}^{-1}$

and $72 \mathrm{mV}$, respectively, suggesting the similar reaction processes for both electrode materials. The charge transfer at the interface of the MWNT film and the electrolyte is as high as Pt electrode because of the fast kinetics [33], which is probably due to one-dimensional nanostructure, good crystallinity, and high localized electron density of states near the Fermi level with MWNT $[8,34]$.
Figure 4a shows the I-shaped TECs for performance investigations. The Seebeck coefficient can be described by the thermodynamics equation of the redox couple as follows: $S=\triangle V / \triangle T=\triangle S_{\mathrm{B}, \mathrm{A}} /(n f)$, where $S$ represents the Seebeck coefficient of the given redox couple, and $\triangle T$ are the electrode potential and the temperature difference between the two electrodes, respectively, $\triangle S_{\mathrm{B}, \mathrm{A}}$ is the reaction entropy of the redox reaction, $n$ is the number of transferred electrons of the reaction, and $f$ is Faraday's constant. The Seebeck coefficient is constant for certain electrolyte, no matter what type of electrode $\mathrm{Pt}$ or MWNTs/SS is selected. $V_{\mathrm{oc}}(\triangle V)$ is generated from the temperature difference between the two electrodes. As shown in Fig. $4 \mathrm{~b}, V_{\mathrm{oc}}$ and $\triangle T$ show linear relationship and the Seebeck coefficient was $1.42 \mathrm{mV} \mathrm{K}^{-1}$, in good agreement with previous reports [6, 8, 9].

Figure $4 \mathrm{c}$ shows that the current densities increased with the temperature differences, and $J_{\mathrm{SC}}$ of the MWNT electrode was about $50 \%$ higher than that of the Pt electrode at the same temperature difference, contributed to good conductivity and high specific surface area for the MWNT film. Under the temperature difference of $50{ }^{\circ} \mathrm{C}, J_{\mathrm{SC}}$ and $J_{\mathrm{SC}} / \Delta T$ reached $45.2 \mathrm{~A} \mathrm{~m}^{-2}$ and $0.91 \mathrm{~A} \mathrm{~m}^{-2} \mathrm{~K}^{-1}$ for
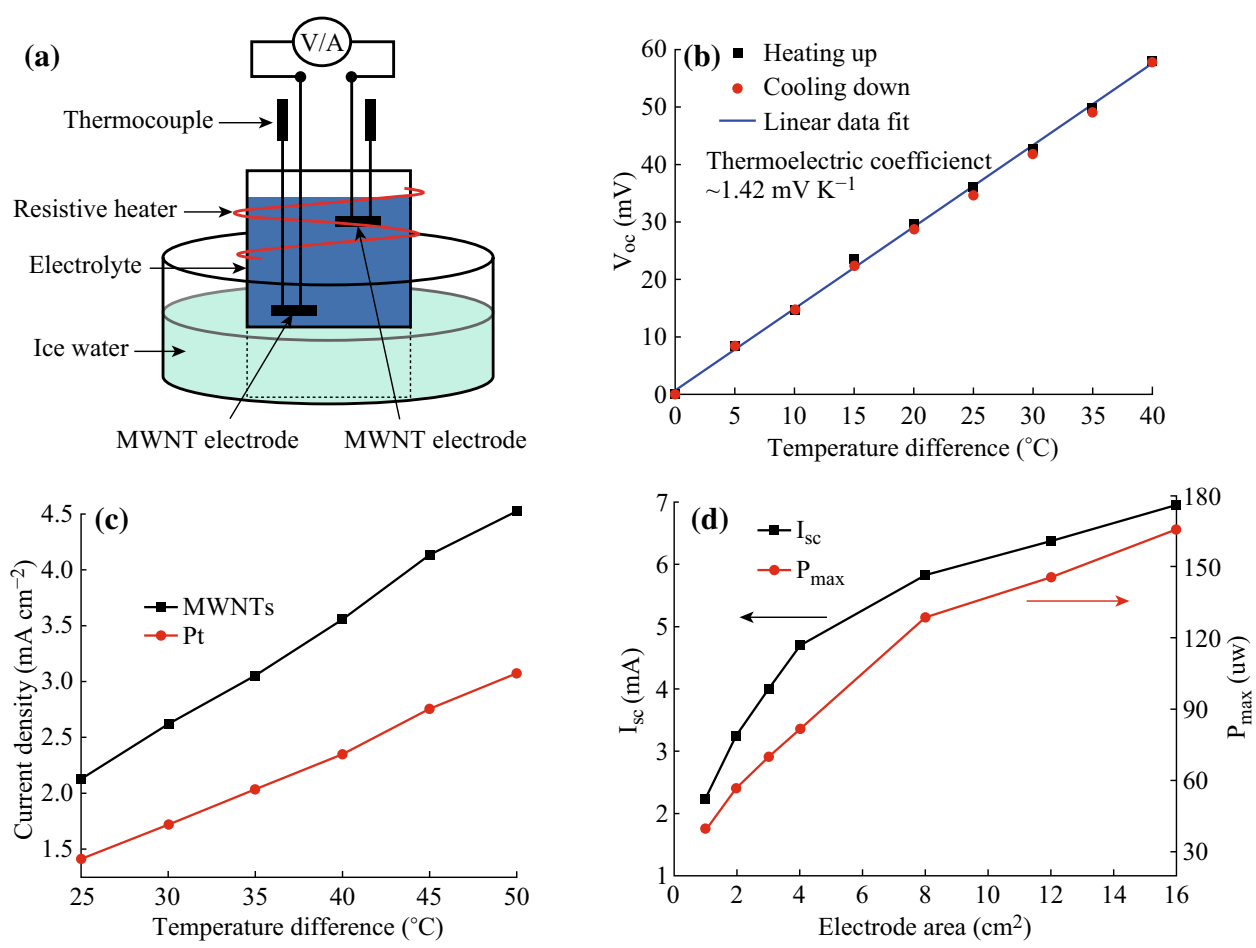

Fig. 4 a Experimental setup for TEC performance measurements. b Thermoelectric coefficient measurements for $0.4 \mathrm{M}$ ferro/ferricyanide $\left(\mathrm{Fe}(\mathrm{CN})_{6}^{4-} / \mathrm{Fe}(\mathrm{CN})_{6}^{3-}\right)$ redox couple from the test of the dependence of open-circuit potential on the temperature difference between the hot and cold electrodes. The electrode area was $0.25 \mathrm{~cm}^{2}$ and the inter-electrode spacing was $4 \mathrm{~cm}$. c $J_{\mathrm{SC}}$ versus temperature difference between electrodes. The distance between electrodes was $5 \mathrm{~cm}$, and the electrode area was $0.4 \mathrm{~cm}^{2}$. d $I_{\mathrm{sc}}$ and $P_{\max }$ versus MWNT electrode areas. Temperature difference was $40{ }^{\circ} \mathrm{C}$ and the inter-electrode distance was $4 \mathrm{~cm}$ 

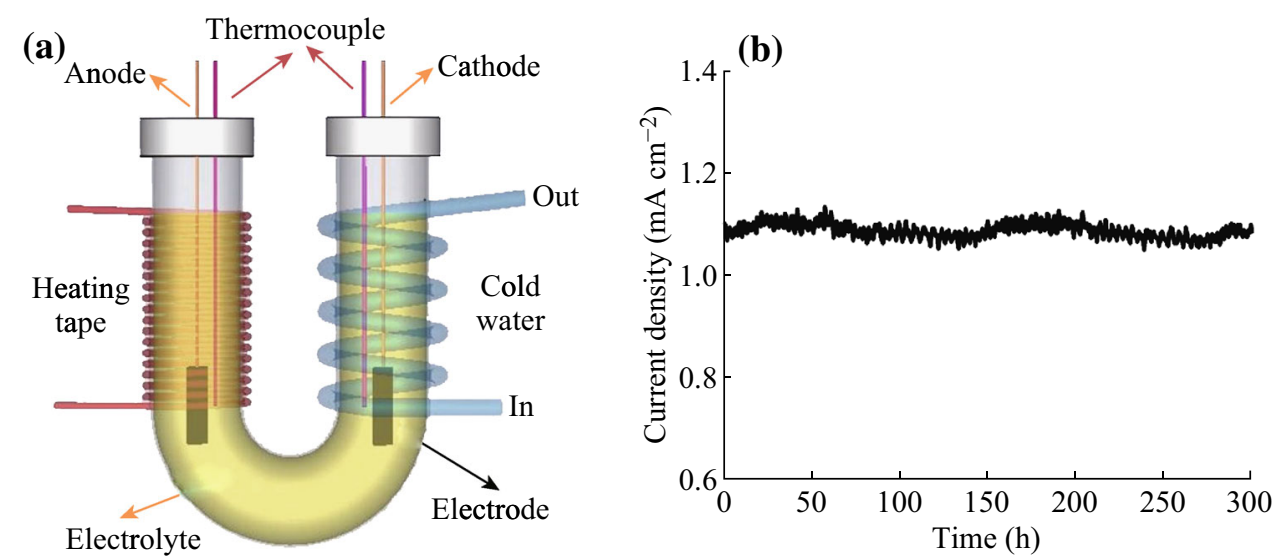

Fig. 5 a The U-Shaped cell for long-term stability test. The distance between two electrodes was $7 \mathrm{~cm}$ and temperature difference was $15{ }^{\circ} \mathrm{C}$. Cold side temperature was controlled by a recirculation water chiller under $T_{\text {cold }}$ of $25{ }^{\circ} \mathrm{C}$, and the hot side temperature was controlled by a resistive heater under $T_{\mathrm{hot}}$ of $40{ }^{\circ} \mathrm{C}$. b $J_{\mathrm{SC}}$ stability over $300 \mathrm{~h}$

MWNT electrodes, comparing with $30.5 \mathrm{~A} \mathrm{~m}^{-2}$ and 0.61 A $\mathrm{m}^{-2} \mathrm{~K}^{-1}$ for Pt electrodes.

To evaluate the performances of the MWNT-based TECs, the power conversion efficiencies $\eta$, expressed below, are calculated for both electrodes [22, 35, 36]:

$\eta=\frac{0.25 V_{o c} I_{s c}}{A K(\Delta T / d)}$

$\eta_{r}=\eta /\left(\Delta T / \Delta_{h}\right)$,

where $A$ is the electrode front area, $k$ is the thermal conductivity of the electrolyte, $\triangle T$ and $d$ are the temperature difference and the distance between electrodes, respectively, $\eta_{\mathrm{r}}$ is the energy conversion efficiency compared to carnot efficiency, and $T_{\mathrm{h}}$ is the temperature of the hot side, measured from the front surfaces of the electrodes. The $\eta_{\mathrm{r}}$ for the MWNT electrode is $0.9,50 \%$ higher than that for the $\mathrm{Pt}$ electrode and similar with the results reported by $\mathrm{Hu}$ [8], which might be due to higher conductivity and lower thermal resistance at electrode/substrate junctions and better ESA of the MWNT electrode $[8,31]$. To obtain an optimized output energy from TECs, it is important to ensure that the temperature drop occur mainly between the electrodes, rather than across the bodies of two electrodes [8]. In order to eliminate the temperature loss, one of the most effective methods is to minimize the thermal resistance of the working electrodes.

In our experiment, the thermal resistance at the MWNT film/substrate junction was $0.0952 \mathrm{~cm}^{2} \mathrm{~K} \mathrm{~W}^{-1}$ under the substrate thickness of $500 \mu \mathrm{m}$ measured by the transient hot wire method. Such a relative high thermal resistance weakens the performance improvement comparing with CVD growth of MWNT film, as shown in SI-2 of the ESI. Further efforts on the reduction of substrate thickness and improvement of the CNT purity are expected to enhance the thermal conductivity of the junction.
Normally, it is difficult to produce large area CNT electrode by CVD method due to growth non-uniformity and facility limitation. EPD technique is able to produce CNT films with large dimensions from simple setup. In this study, different sizes of MWNT electrodes were prepared by EPD to conduct the performance investigation. As shown in Fig. 4d, the lager the electrode area, the higher the output current and power, benefited from the increase of reaction sites [8]. When the electrode area was increased to $16 \mathrm{~cm}^{2}$, the output current and power could reach $7.0 \mathrm{~mA}$ and $166 \mu \mathrm{W}$, respectively, at the temperature difference of $40{ }^{\circ} \mathrm{C}$. However, the increasing rates of $I_{\mathrm{sc}}$ and $P_{\max }$, where $P_{\max }$ was obtained by $1 / 4 V_{\mathrm{oc}} \times I_{\mathrm{sc}}$, declined gradually with the increase of surface area. Two factors, i.e., the edge effect of the CNT film [37] and the drop of MWNT density, may cause this nonlinear relation. Interestingly, the Seebeck coefficient increased from 1.42 to $2.40 \mathrm{mV} \mathrm{K}^{-1}$ with raising the surface area from 1 to $16 \mathrm{~cm}^{2}$, probably due to the concentration effect of the cell [6]. In our test system (hot-above-cold, see Fig. 4a), the buildup concentration would become obvious with increasing the surface area of the MWNT electrode, exhibiting partly the properties of the concentration cell [6]. Therefore, further efforts should be conducted to improve the TECs performances with large electrode area, e.g., trying to overcome the concentration effect with designs such as the flowing TECs $[8,38]$ or the cold-abovehot TECs [9]. The relation between the output power and the voltage is shown in the ESI as SI-1.

If TECs were operated in an open system over a long period of time, the potassium ferrocyanide/ferricyanide solution would evaporate gradually, resulting in the current instability from the change of the electrolyte concentration. The TECs of closed system could operate with enhanced 
long-term stability [8]. In this work, the U-Shaped close system TECs with MWNT electrodes were employed to evaluate the long-term performance (see Fig. 5a). As shown in Fig. 5b, the U-shaped TEC discharged continuously for $300 \mathrm{~h}$ with no current degradation. The excellent discharge stability is benefited mainly from two aspects. At first, because the electrolyte in this system could reach equilibrium quickly, the concentration gradient from the mass transport kept almost unchanged during the operation [8, 31]. Secondly, the ESA of the MWNT film was stable during the operation of TECs due to the structure stability, showing strong adhesion between the MWNT film and the SS substrate. The excellent discharge property revealed great potential of the EPD production of CNT film for practical TEC electrodes.

\section{Conclusions}

EPD is an efficient technique to produce MWNT electrodes for TECs applications. The relative power conversion efficiency of the MWNT TECs is $50 \%$ higher than that of the platinum electrode-based TECs, while the excellent long-term current stability revealed the durability of the MWNT film. Furthermore, the low cost and large-scale production capabilities may promote the energy harvesting in various fields.

Acknowledgments This work is partially financial supported by National Science Foundation of China (No. 11274244, 51302193).

Open Access This article is distributed under the terms of the Creative Commons Attribution 4.0 International License (http://crea tivecommons.org/licenses/by/4.0/), which permits unrestricted use, distribution, and reproduction in any medium, provided you give appropriate credit to the original author(s) and the source, provide a link to the Creative Commons license, and indicate if changes were made.

\section{References}

1. C.B. Vining, An inconvenient truth about thermoelectrics. Nat. Mater. 8, 83 (2009). doi:10.1038/nmat2361

2. T. Mancini, P. Heller, B. Butler, Dish-stirling systems: an overview of development and status. J. Sol. Energy Eng. 125(2), 135-151 (2003). doi:10.1115/1.1562634

3. M. Ujihara, G.P. Carman, D.G. Lee, Thermal energy harvesting device using ferromagnetic materials. Appl. Phys. Lett. 91(9), 093508 (2007). doi:10.1063/1.2775096

4. D.A.W. Barton, S.G. Burrow, L.R. Clare, Energy harvesting from vibrations with a nonlinear oscillator. J. Vib. Acoust. 132(2), 021009 (2010). doi:10.1115/1.4000809

5. H.G. Hertz, S.K. Ratkje, Theory of thermocells. J. Electrochem. Soc. 136(6), 1698-1704 (1989). doi:10.1149/1.2096995

6. T.I. Quickenden, Y. Mua, A review of power generation in aqueous thermogalvanic cells. J. Electrochem. Soc. 142(11), 3985-3994 (1995). doi:10.1149/1.2048446
7. T.J. Abraham, D.R. MacFarlane, J.M. Pringle, Seebeck coefficients in ionic liquids-prospects for thermo-electrochemical cells. Chem. Commun. 47(22), 6260 (2011). doi:10.1039/c1cc11501d

8. R.C. Hu, B.A. Cola, N. Haram, J.N. Barisci, S. Lee et al., Harvesting waste thermal energy using a carbon-nanotube-based thermo-electrochemical cell. Nano Lett. 10(3), 838-846 (2010). doi:10.1021/n1903267n

9. T.J. Kang, S.L. Fang, M.E. Kozlov, C.S. Haines, N. Li, Y.H. Kim, Y.S. Chen, R.H. Baughman, Electrical power from nanotube and graphene electrochemical thermal energy harvesters. Adv. Funct. Mater. 22(3), 477-489 (2012). doi:10.1002/adfm. 201101639

10. S. Iijima, Helical microtubules of graphitic carbon. Nature 35, 56-58 (1991). doi:10.1038/354056a0

11. R.H. Baughman, A.A. Zakhidov, W.A. de Heer, Carbon nanotubes-the route toward applications. Science 29(5582), 787-792 (2002). doi:10.1126/science.1060928

12. Q. Cao, J.A. Rogers, Ultrathin films of single-walled carbon nanotubes for electronics and sensors: a review of fundamental and applied aspects. Adv. Mater. 21(1), 29-53 (2009). doi:10. 1002/adma.200801995

13. Junjun Chen, Xu Xiangju, Lijie Zhang, Shaoming Huang, Controlling the diameter of single-walled carbon nanotubes by improving the dispersion of the uniform catalyst nanoparticles on substrate. Nano-Micro Lett. 7(4), 353-359 (2015). doi:10.1007/ s40820-015-0050-8

14. G.M. Zhou, F. Li, H.M. Cheng, Progress in flexible lithium batteries and future prospects. Energy Environ. Sci. 7(12), 1307-1338 (2014). doi:10.1039/C3EE43182G

15. B.J. Landi, M.J. Ganter, C.D. Cress, R.A. DiLeo, R.P. Raffaelle, Carbon nanotubes for lithium ion batteries. Energy Environ. Sci. 2(12), 638-654 (2009). doi:10.1039/b904116h

16. Xiaobing Zhang, Ji Ma, Kezheng Chen, Impact of morphology of conductive agent and anode material on lithium storage properties. Nano-Micro Lett. 7(4), 360-367 (2015). doi:10.1007/ s40820-015-0051-7

17. W. Xiong, F. Du, Y. Liu, A. Jr, M. Perez, T.S. Supp, L.M. Ramakrishnan, L.Jiang Dai, 3-D carbon nanotube structures used as high performance catalyst for oxygen reduction reaction. J. Am. Chem. Soc. 132(45), 15839-15841 (2010). doi:10.1021/ ja104425h

18. Y.P. Zhang, J. Sun, Y.Y. Hu, S.Z. Li, Q. Xu, Carbon nanotubecoated stainless steel mesh for enhanced oxygen reduction in biocathode microbial fuel cells. J. Power Sources 239, 169-174 (2013). doi:10.1016/j.jpowsour.2013.03.115

19. T.J. Abraham, N. Tachikawa, D.R. MacFarlane, J.M. Pringle, Investigation of the kinetic and mass transport limitations in thermo electrochemical cells with different electrode materials. Phys. Chem. Chem. Phys. 16(48), 2527-2532 (2014). doi:10. 1039/C3CP54577F

20. P.F. Salazar, S. Kumar, B.A. Cola, Design and optimization of thermo-electrochemical cells. J. Appl. Electrochem. 44(2), 325-336 (2014). doi:10.1007/s10800-013-0638-y

21. T.J. Abraham, D.R. MacFarlane, J.M. Pringle, Huge seebeck coefficients in nonaqueous electrolytes. J. Chem. Phys. 134(11), 114513 (2011). doi:10.1063/1.3561735

22. S. Manda, A. Saini, S. Khaleeq, R. Patal, B. Usmani, S. Harinipriya, B. Pratiher, B. Roy, Thermocells of carbon material electrodes and its performance characteristics. J. Mater. Res. Technol. 2(2), 165-181 (2013). doi:10.1016/j.jmrt.2013.01.005

23. H.D. Yang, L.T. Tufa, K.M. Bae, T.J. Kang, A tubing shaped, flexible thermal energy harvester based on a carbon nanotube sheet electrode. Carbon 86, 118-123 (2015). doi:10.1016/j.car bon.2015.01.037

24. B.A.R. Occaccini, J. Cho, J.A. Roether, B.J.C. Thomas, E.J. Minay, M.S.P. Shaffer, Electrophoretic deposition of carbon 
nanotubes. Carbon 44(15), 3149-3160 (2006). doi:10.1016/j.car bon.2006.06.021

25. A.A. Talin, K.A. Dean, S.M. O'Rourke, B.F. Coll, M. Stainer, R. Subrahmanya, FED cathode structure using electrophoretic deposition and method of fabrication, U.S. Patent 10/024,164, 7 June 2005

26. S.G. Oh, J. Zhang, Y. Cheng, H. Shimoda, O. Zhou, Liquid-phase fabrication of patterned carbon nanotube field emission cathodes. Appl. Phys. Lett. 84(19), 3738 (2004). doi:10.1063/1.1737074

27. J.S. Corneille, J.W. He, D.W. Goodman, XPS characterization of ultra-thin $\mathrm{MgO}$ films on a Mo (100) surface. Surf. Sci. 36(3), 269-278 (1994). doi:10.1016/0039-6028(94)90071-X

28. X.B. Yan, T. Xu, S.R. Yang, H.W. Liu, Q.J. Xue, Characterization of hydrogenated diamond-like carbon films electrochemically deposited on a silicon substrate. J. Phys. D 37(17), 2416-2424 (2004). doi:10.1088/0022-3727/37/17/012

29. G. Carta, N.E. Habra, L. Crociani, G. Rossetto, P. Zanella, A. Zanella, G. Paolucci, D. Barreca, E. Tondello, CVD of MgO thin films from bis(methylcyclopentadienyl) magnesium. Chem. Vap. Depos. 13(4), 185-189 (2007). doi:10.1002/cvde.200606574

30. A.J. Bard, L.R. Faulkner, Electrochamical methods-fundamentals and applications (Wiley, New York, 2001), pp. 1-814

31. M.S. Romano, N. Li, D. Antiohos, J.M. Razal, A. Nattestad et al., Carbon nanotube-reduced graphene oxide composites for thermal energy harvesting applications. Adv. Mater. 25(45), 6602-6606 (2013). doi:10.1002/adma.201303295
32. P.F. Salazar, S. Kumar, B.A. Cola, Nitrogen-and boron-doped carbon nanotube electrodes in a thermo-electrochemical cell. J. Electrochem. Soc. 159(5), B483-B488 (2012). doi:10.1149/2. 043205jes

33. J.M. Nugent, K.S.V. Santhanam, A. Rubio, P.M. Ajayan, Fast electron transfer kinetics on multiwalled carbon nanotube microbundle electrodes. Nano Lett. 1(2), 87-91 (2001). doi:10. $1021 / \mathrm{n} 1005521 \mathrm{z}$

34. C. Schonenberger, A. Bachtold, C. Strunk, J.P. Salvetat, L. Forro, Interference and interaction in multi-wall carbon nanotubes. Appl. Phys. A 69(3), 283-295 (1999). doi:10.1007/s003390051003

35. T.I. Quickenden, C.F. Vernon, Thermogalvanic conversion of heat to electricity. Sol. Energy 36(1), 63-72 (1986). doi:10.1016/ 0038-092X(86)90061-7

36. M.S. Romano, S. Gambhir, J.M. Razal, A. Gestos, G.G. Wallace, J. Chen, Novel carbon materials for thermal energy harvesting. J. Therm. Anal. Calorim. 109(3), 1229-1235 (2012). doi:10.1007/ s10973-012-2311-9

37. I. Corni, N. Neumann, D. Eifler, A.R. Boccaccini, Polyetheretherketone (PEEK) coatings on stainless steel by electrophoretic deposition. Adv. Eng. Mater. 10(6), 559-564 (2008). doi:10.1002/adem.200800010

38. H. Im, H.G. Moon, J.S. Lee, I.Y. Chung, T.J. Kang, Y.H. Kim, Flexible thermocells for utilization of body heat. Nano Res. 7(4), 443-452 (2014). doi:10.1007/s12274-014-0410-6 